\title{
Facilitating Learning through PBL in a Chinese Context: Students' Learning Outcomes and Attitudes
}

\author{
Huichun Li \\ Research Institute for Higher Education \\ Fudan University, China
}

\begin{abstract}
Instituting PBL in different national and cultural contexts can be a challenging task. This study explores PBL (problem based learning) implementation in a single disciplinary course in the domain of humanities in China, with a particular focus on students' learning outcomes and their attitudes towards PBL. A qualitative research approach is adopted for data collection and analysis. We have conducted 14 interviews and collected all students' final project products as complementary data source. The main findings are: firstly, PBL leads to better learning outcomes in terms of interdisciplinary learning, self-directed learning, problem solving, creative thinking, communication, as well as knowledge retention; secondly, students' attitudes towards PBL differ: although some students favour PBL approach, other students tend to have mixed attitudes towards PBL and somehow stick to the value of conventional educational approach. To enhance students' recognition of PBL in China, one needs not only to show students the effectiveness of PBL, but also to transform the conception of learning in students' mind.
\end{abstract}

Keywords: PBL; problem based learning; Chinese context; learning outcome; attitude.

\section{Introduction}

PBL has developed for over four decades and now is implemented in various disciplinary fields, institutions, as well as national contexts. PBL marks itself by problem based learning, interdisciplinary learning, self-direct learning, teamwork and so on (De Graaff \& Kolmos, 2003). Many attempts have been made to investigate the effectiveness of PBL, and have found that PBL approach is quite promising in enhancing student learning outcomes, promoting student learning motivation, as well as altering student learning habits (Blumberg \& Michael, 1992; Dolmans \& Schmidt, 1996; Dochy et al., 2003; Tiwari et al., 2006; 
Strobel \& van Barneveld, 2009; Du, Su \& Liu, 2013). However, the students' learning outcome and their attitude towards PBL is partly dependent on national and cultural context. Therefore, to what extent PBL can show its strength across different national context remains an issue. Frambach et al. (2014) argue that the merits of PBL can be confirmed somehow across different national and cultural background, but the process and the result may differ significantly. In recent years, PBL has been introduced in the higher education institutions in China so as to enhance students' learning outcomes and changing their learning behaviour; however, few researches are conducted on the value of and students' attitude towards PBL in China, especially in the non-medical domain. This study documents and explores the PBL implementation in a single disciplinary course in the domain of humanities in China, with a particular focus on students' learning outcomes of and their attitude towards PBL.

\section{State of art}

Research field is abundant with studies on PBL. Given the purpose of this research, the literature review is focusing on PBL and its forms, the value of PBL, students' attitudes toward PBL, and issues emerging with regard to PBL implementation in China.

\subsection{PBL and its forms}

PBL originates from McMaster University in Canada in the late 1960s as an alternative educational approach to traditional teacher-centered educational method (Savin-Baden \& Major, 2004). There are a great number of attempts addressing the meaning of PBL (Barrows \& Tamblyn, 1980; Boud, 1985; Dolmans et al., 2005; Kolmos, 2008). Barrows and Tamblyn (1980) identify PBL as having five features: complex and real-world situations, group work, knowledge acquisition through self-directed learning, teachers-serve as facilitators, and problems directing capacity development. Boud (1985) adds complexity to the meaning of PBL by outlining eight crucial elements of PBL: acknowledging learners' experience, highlighting students taking responsibility for learning, interdisciplinary learning, connecting theory to practice, emphasizing learning process other than learning products, a teacher serving as a facilitator rather than an instructor, favoring self and peer assessment, valuing communication and interpersonal skills. De Graaff and Kolmos (2003) consider PBL as being centered upon some learning principles, in terms of problem based learning, participant-directed study, experience learning, activity based learning, interdisciplinary study, exemplary practice and group work. Dolmans et al. (2005) define PBL as being constructive, self-directed, collaborative and contextual. Despite all the differences of these clarifications, it can be found that PBL share some commonalities, as noted by Kolmos (2008), in terms of a learning perspective based on dealing with problems, a content perspective manifested by learning across different disciplinary domains, and social learning through group work. The learning perspective means that the learning of PBL is centered on problems rather than disciplinary knowledge. The problem is set as the departure of the learning process; dealing with the problem afterwards directs the whole learning process. The content perspective refers to an interdisciplinary approach which allows learners to integrate the knowledge and 
the methods from different fields while addressing the problem. The social learning is based upon social constructivism (Savin-Baden \& Major, 2004), presuming knowledge is developed through the interaction among different learners, stimulating students to work in groups.

The uses of PBL vary significantly. PBL could take various forms and be used at different levels (Kolmos, 1996; Savin-Baden, 2003; Moesby, 2004; Li \& Du, 2018). In medical field, PBL usually occurs in the form of case-based study (Barrows \& Tamblyn, 1980) where a medical problem (such as a symptom) comes first, afterwards students gain knowledge and skills by addressing the problem. However, in science and engineering field, PBL usually takes the form of project work. By combining PBL and project work together, some higher education institutions develop a problem-based project-organized learning model (PBPOL) (Kolmos, Fink \& Krog, 2004; Barge, 2010). However, how PBL is organized is heavily dependent upon one's conception of the problem, which produces further impact upon the design of the PBL and students' learning process (Henriksen et al., 2004). PBL could also be used at different levels, such as a single course level, multiple course level, or even a whole program (Moesby, 2004). The merits of different PBL approaches vary significantly, as Moesby (2004) suggests, the holistic PBL approach can make more benefits than the PBL in a single course.

\subsection{The value of PBL}

The value of PBL has been increasingly recognized in terms of promoting students' learning outcomes, changing students' learning attitudes and altering their learning habits, etc. (Dolmans \& Schmidt, 1996; Dochy et al., 2003; Tiwari et al., 2006; Strobel \& van Barneveld, 2009). Many researches focus PBL value on its influence on student learning outcome. Tiwari et al. (2006) show students' significant improvement in critical thinking after they take PBL classes. Strobel and van Barneveld's (2009) study with regard to the learning outcome comparison between traditional approach and PBL approach note that PBL students perform better than traditionally taught students, such as long-term information retention, skill-oriented competence, and blended development of both knowledge and skills. Woods (2012) note that PBL could lead to better skill development in the clinical, trouble shooting, problem solving and teamwork, higher confidence, lifelong learning and motivation, better long term knowledge retention, and better development of deep learning. Preeti, Ashish and Shriram (2013) document that the majority of students tend to agree that PBL results in better interest, better understanding of knowledge and better self-directed learning skills. Zhou, Kolmos and Nielsen (2012) find that compared to traditional education method, PBL can serve as a useful way to develop students' creative thinking skills. Du, Su and Liu (2013) argue that PBL is beneficial for participative learning, critically reflecting, systematical thinking, as well as sustainable competence. Alrahlah (2016) argues that PBL students exhibit better professional skills and effective learning compared with those taught by traditional approaches. Even so, Savin-Baden (2000: 26) still insists that the merits of PBL to students, staff members and employers have been underestimated to a large extent. 


\subsection{Students' attitudes toward PBL}

Many studies have been carried out with regard to students' attitudes towards PBL and traditional teaching method and on their learning habits transformation after they taking PBL courses. PBL is believed to be advantageous in dealing with negative student attitudes towards learning, students' motivation in daily performance and attrition issue. The students from PBL contexts are likely to possess a more positive attitude towards their learning environment than those in traditional programs (De Vries, Schmidt, \& de Graaff, 1989). PBL students more frequently use textbooks and engage in informal discussions with peer learner than their counterparts more relying on lecture notes (Blumberg \& Michael, 1992). Further, Bernstein et al. (1995) notice that the students after taking PBL classes show an increase in favorable comments on PBL. The students regard traditional methods as more effective in maintaining knowledge acquisition, whereas perceive PBL as better for teamwork and doctor-patient relationship improvement. Similarly, Kaufman and Mann (1996) note that PBL students are more satisfied with their curriculum, in particular, their learning environment, since they feel more enthusiasm and ownership in PBL context. They also notice that compared to conventionally-teaching students, the PBL class is more fond of basic sciences (Kaufman \& Mann, 1997). Klegeris and Hurren (2011) demonstrate that PBL can better improve students' attendance in the class and their involvement in learning and it is superior to traditional lecture in terms of understanding course content and knowledge retention. Mohan et al. (2014) conduct a comparative study between students' towards PBL and traditional teaching and note that the students lean towards PBL instead of traditional lectures.

\subsection{PBL implemented in Chinese context}

Due to its western origin, the cross-cultural application of PBL becomes a big concern for many researchers (Walker, Bridges \& Chan, 1996; Hallinger \& Lu, 2011; Frambach et al., 2012). Several empirical studies conducted in different national and regional contexts investigate PBL effectiveness in enhancing students' learning outcome and learning motivation; however, little consensus is reached on the learning processes and outcomes of the students (Frambach et al., 2014). Given the particular national and cultural context, if researchers attempt to generalize the findings from western contexts to Asian countries such as China, more researches need to be conducted regarding PBL implementation and its effectiveness in China.

PBL is introduced into the Chinese context in recent years. Medical education is a domain where many teachers and curriculum designers carry out PBL experiment, both at a course level (Wang et al., 2008) or even at the institutional level ( $\mathrm{Li}, 2013)$. Literature shows that the use of PBL in China is mainly centered on medical field. A survey (Fan et al., 2014) notes that a large majority of Chinese medical institutes (34 of 43) use PBL; however, the application of PBL is quite limited since PBL only takes up less than half of whole curricular hours before clinical phase in most institutes. There are quite few researches document PBL in non-medical field (e.g. Du, Su \& Liu, 2013; Zhan, 2018). 
The introduction of PBL into Chinese education system can be a challenging task, since there is a tension or collision between Chinese context and the essence of PBL. Firstly, Chinese educational system favours the design of traditional discipline-based courses which highlight the delivery of disciplinary knowledge by individual teachers, and somehow discourages collaborative curriculum development and team teaching. Moreover, how people perceive teachers' role and their relationship with students in China also produces significant impact upon the implementation of PBL. Traditional teacher-student relationship highlighting teachers' dominance over teaching and learning process may undermine the implementation of PBL which requires the teachers to change their role from the instructor to the facilitator $(\mathrm{Li} \& \mathrm{Du}, 2013)$. Chinese teachers may recognize the value of granting autonomy to students, however, they are still likely to maintain high interference with student learning process ( $\mathrm{Li} \& \mathrm{Du}$, 2015), which is inherently contradictory to the spirit of PBL emphasizing student-directed learning (De Graaff \& Kolmos, 2003). Thirdly, some researchers reveal that students learning attitude and habit have negative impact on PBL implementation. Chinese students are exposed to exam-oriented education in China since their childhood which deeply shapes their conception of learning as knowledge acquisition and passing exams (Kirkpatrick \& Zang, 2011). Therefore, Chinese students are quite accustomed to passive learning, following teachers' instructions, and respecting teachers' authority, which hamper PBL implementation to a large extent (Wang et al., 2008).

\section{Research design}

This study aims at investigating students' learning outcomes of and their attitudes towards PBL in the Chinese context. A single disciplinary course in the domain of humanities is taken as research object and a qualitative approach is adopted for data collection and analysis.

\subsection{Research site and the course design}

This study takes Higher Education History course at the Department of $\mathrm{H}$ of University $\mathrm{F}$ in China as an example. Traditionally, this course took the form of pure lectures, aiming at depicting the historical development of higher education thoughts and institutions, helping students get a basic understanding of the most important figures, events, and thoughts in the domain of higher education across different countries. In 2017, PBL elements were introduced into this course. This course started with the teacher giving lectures beforehand for approximately three months, offering the basic knowledge as scaffolding PBL work. Afterwards, the students taking this course were given two weeks by the teacher to work on an independent PBL project, similar to what is categorized as problem-based project-organized learning (Kolmos, Fink, \& Krog, 2004; Barge, 2010). Students were expected to develop their own learning objectives, arrange the whole learning process, and finally finish the project. After completing the PBL project work, the students are required to submit all their final project products, and to present their project work in class. The students are allowed decide their learning objectives, the form of their project work, and arrange their learning process. The teacher only serves as a facilitator or an observer. 
It should be noted that PBL developed in this course is a bit different from some classic PBL approaches: 1) The PBL in this course falls into the PBL category as the single course PBL, classified by Moesby (2004). The PBL elements in this study are only applied to one single disciplinary course and not institutionally coordinating with other courses. Therefore, part of the research intention is to explore if interdisciplinary learning can be fostered by a single PBL course within the Chinese context. 2) A common trait of PBL is social learning (Kolmos, 2008) which means that students should work on the problem in the form of groups. However, in this research, due to some institution constrains, teamwork cannot be introduced in the course, and therefore this study rolls out group work element and let the students conduct a completely independent PBL project work.

\subsection{Data collection}

This study is mainly conducted in a qualitative manner. Interviews are employed as the primary method for data collection. The interview is essentially beneficial for the exploration of people's comprehension of an event and phenomenon with its particularity and their experiences (Cohen, Manion \& Morrison, 2007). Semi-structured interviews are employed and the students are expected to report their attitude, their involvement, their learning process, as well as their learning outcomes with regard to PBL based on their own experience and observation. Interview questions are centered on two major topics in terms of the students' learning outcomes and their attitudes towards PBL work and traditional work (lecture based work).

Further, all the final project products are collected as complementary data source which could be utilized to analyze what kinds of disciplinary knowledge the students apply to address the problem. The triangulation principle indicates that the validity of an argument can be further increased when it is confirmed by difference data sources (Creswell, 2009). In this sense, the interview and the students' project work could validate the arguments about their learning outcomes by giving evidence from different perspectives.

In total, this study is composed of 14 interviews ( 2 male students and 12 female students) which are transcribed and manually coded in English. All quotations are categorized into different themes, and the key conceptions are emphasized in each category and corresponding with students' conceptions of PBL.

\section{Research findings}

In total, this study finds that the PBL students show better learning outcomes in terms of interdisciplinary learning, self-directed learning skills, problem solving skills, creative thinking, communication skills, as well as knowledge retention. However, their attitudes towards PBL seem to be differing significantly.

\subsection{Learning outcomes}

This PBL project work shows great strength in facilitating students' skill development and knowledge retention. It is demonstrated that through PBL project work, all the students have developed their skills (see Table 1), such as interdisciplinary learning, self-directed learning, problem solving skills, creative 
thinking, and communication. It is surprisingly notice that over half of the students (8 out of 14) perceive knowledge retention as one of PBL work's major strengths.

Table 1: Skills developed after taking PBL course

\begin{tabular}{|c|c|}
\hline Skills types & $\begin{array}{c}\text { No. of student } \\
\text { reported }\end{array}$ \\
\hline interdisciplinary skills & 9 \\
\hline self-directed learning skills & 7 \\
\hline problem solving skills & 7 \\
\hline creative thinking stills & 7 \\
\hline communication skills & 6 \\
\hline knowledge retention & 8 \\
\hline
\end{tabular}

Interdisciplinary learning is the most frequently mentioned skill that the students have developed through PBL work, as the students comment "this project work helps me integrate what I learn in this course with other knowledge content outside this classroom". "During the project work, I search a lot of sources and thus expand my knowledge in another field." "It helps me to demonstrate what I learn in a lot of forms other than my own disciplinary field." However, what kinds of knowledge can be integrated in the PBL project work and to what extent the knowledge can be integrated in the study is highly dependent on students. For instance, one student chooses to visualize her project work in the form of a computer video game since she has a computer science background. By doing so, she is able to link what she has learned from the history course to her past computer science experience.

Self-directed learning skills and problem solving skills are often intertwined. The students may develop their problem solving skills by engaging in a lot of participant-directed learning activities. It is these activities that make students address problem scenario on their own, manage their own learning process, and participate in hands-on activities. As the comments from the students show, the PBL project work can "help me dealing with the practical situation" "integrate different knowledge to solve the problem" "I need to do a lot of work completely on my own".

Creative thinking skills can be fostered through PBL working process. When the students link knowledge content from different areas and engaging in selfdirected learning activities, they are more likely to produce something new. Some students express their excitement after they finish their work, such as "it is a good chance to develop my creative thinking skills through this work" "I can make something new and totally original."

Communication skills are also mentioned by many students. Thought it is an individual work, the students are still able to develop their communication skills since they have to finish the project work and make presentations to other peers, as some students reply, "I need to communicate some elements of my work in 
an interdisciplinary manner" "I consider various possible forms of communication during my work, which is challenging but also rewarding".

Knowledge retention is surprisingly regarded as one of PBL's major strengths. It is worth noting that some students attach the value of promoting knowledge retention to PBL. As one student says, "During this process, I become more familiar with the knowledge, and thus get a much more deep understanding of the knowledge." The process of the knowledge retention within PBL context is not just memorizing knowledge content but linking to a rather complicated cognitive process, as another student recalls, "the project work gives me a good chance to go through all the content that I have learned, I have to restructure them, I have to connect them to something that I got besides this course." It is worth mentioning that related to knowledge retention issue is that a few students even wish the teacher to deliver them more knowledge because "the knowledge given to us so far is not enough."

\subsection{Students' attitudes towards PBL project work and traditional work}

The students' attitudes towards PBL work and traditional work differs. Half of the students (7 out of 14) express positive attitudes towards PBL environment since PBL can activate their previous knowledge, or even their previous experience outside the classroom. As a student replies, "this project work can help me connect what I learning in this course to my past academic background. I even can use some elements of my personal interest in doing this work." Other positive comments on PBL include PBL can "help us develop our practitioner skills" "encourage self-directed learning skills" "expand my knowledge scope" "give me a chance to integrate all the knowledge". However, the other half give more credits to traditional lecture-based work, though they admit the effectiveness of PBL. They insist that traditional lecture work can "give deeper understanding of the knowledge" "deliver knowledge more effectively" "get more guidance from the teacher".

This study tries to quantify students' involvement in PBL by asking them to calculate how many hours they work on the PBL project. It can be noted that the involvement of the students in PBL varies, in a similar way as their attitudes towards PBL work and traditional work. Half of the students spend over 8 hours on the project, and three of them even work on PBL for more than 12 hours (The maximum work hour is 18 hours). Five students report a work time between 4-8 hours, and a few students ( 2 out of 14 ) work less than 4 hours.

\section{Discussion}

It can be noted that PBL implementation in the Chinese context is promising and challenging. On one hand, PBL shows great strength in enhancing students' learning outcomes; on the other hand, it also encounters significant challenges since students have different attitudes towards PBL.

\subsection{Learning outcomes}

Cross-cultural application of PBL has drawn many research interests (Walker Bridges \& Chan, 1996; Hallinger, \& Lu, 2011; Frambach et al., 2012). From this study it can be shown that PBL is effective even in a single disciplinary course, 
leading to an enhancement of student interdisciplinary learning skills, problem solving skills, self-direct learning skills, creative thinking, communication, and knowledge retention. This again confirms that PBL effectiveness can be proved in different national and cultural context (Frambach et al., 2014).

Of all the strengths of PBL project work, interdisciplinary learning is worth more attention. Many researches regard interdisciplinary learning as a basic element of PBL. For instance, Boud (1985) points out that PBL involves "a crossing of boundaries between disciplines", Kolmos (2008) argues that PBL contains a content perspective in terms of interdisciplinary learning. Within PBL context, students need to deal with problem scenarios by applying knowledge and methods from a variety of disciplinary fields. When it comes to PBL curriculum design, some researches show that interdisciplinary learning can be optimistically fostered by a holistic PBL approach (Moesby, 2004). It seems quite challenge to promote interdisciplinary learning when PBL is only implemented at a single course level due to two reasons. Firstly, PBL is often used as a way to examine the knowledge content from the lecture rather than an approach to acquiring new knowledge in PBL of a single disciplinary course. Secondly, there is quite limited collaboration among different courses when PBL is only used in one single course. However, this study reveals that even in a single disciplinary course, interdisciplinary learning can still be realized to a certain degree. It is so because PBL is not a simple learning process seeking for a certain answer or a prescribed body of knowledge; rather, it is a new way of conceptualizing education ( $\mathrm{Li}, 2013)$, requiring a shift of the conception regarding knowledge, learning, and the role of both teacher and student. Within PBL the students need to become active learners, engaging in real life situations and experience learning activities, which make PBL a much complicated cognitive process involving problem solving, exemplary practice, self-directed learning, creative thinking, et al., thus facilitating integration and application of the knowledge content from different fields. As China's higher education institutions still favour the design of single disciplinary courses, the findings of this study show that a single disciplinary course can still promote students' learning outcome by incorporating PBL elements is of significant value for the teachers who wish to make pedagogical innovation and enhance students' skills in terms of interdisciplinary learning, problem-solving, creative thinking, and so on. However, to what extent PBL can enhance interdisciplinary learning, and what kind of disciplinary knowledge is integrated in the learning process, vary according to students' personal traits such as their academic background, personal interest, and the problem solving process. Therefore, more studies need to be conducted on PBL learning process in the Chinese context.

\subsection{Students' mixed attitudes towards PBL}

Chinese students in this study have mixed attitudes towards PBL. On one side, they acknowledge the effectiveness of PBL since they are able to develop a lot of useful skills through PBL project work; on the other side, a few students, who admit the value of PBL, still lean towards traditional lecture based work, when comparing traditional approach with PBL work. They express a lot of concerns of knowledge acquisition issue. There overemphasis on knowledge acquisition can be accounted from several aspects. Firstly, many Chinese students still hold 
a conservative conception of learning as knowledge accumulation rather than practical skill development. The primary and secondary education in China are highly examination oriented, taking knowledge acquisition and pass example as the primary goal of the education (Kirkpatrick \& Zang, 2011), therefore Chinese students are likely to formulate a conception of the learning as memorizing knowledge, which also influences their view of learning in higher education. This conception of learning is somehow contradictory to PBL which highlights real life situation, problem solving, and skill development. While PBL has some strength in enhancing students' knowledge retention, as confirmed by Strobel and van Barneveld's (2009) and Woods (2012), in a general sense, knowledge retention is not the focal point of PBL researches. The reason lies in that PBL aims at promoting students' different skills which enable them to act in real life situation, rather than simply focusing on enhancing knowledge acquisition.

Further, the students' overemphasis on the value of knowledge retention can be accounted by the assessment system in China. The assessment in China's higher education institutes are mainly focusing on knowledge acquisition and students' comprehension of the course content from lectures, and it contains very limited components with regard to skill development. This again reinforces and consolidates Chinese students' conception of learning as accumulation of knowledge. If the teachers want to make PBL more favourable for students, they need to follow the alignment principle proposed by Biggs and Tang (2007) which means that the curriculum designers should reform learning objectives, teaching and learning process, and assessment approach as a whole, instead of adjusting one element and maintain others. Further, Kolmos and De Graaff (2007) point out that the conception change of the people is a complex process which should be treated in a holistic and integrated manner, alongside other elements at the educational system. Therefore, the attitudes transformation of the students towards PBL should be associated with other aspects of the curriculum and the organization, and it cannot be finished on its own.

\section{Conclusion}

This study investigates the students' learning outcomes and their attitudes towards PBL. It can be noticed that even in a single disciplinary course, PBL can still show its strengths in fostering skill development in terms of interdisciplinary learning, self-directed learning, problem solving skills, creative thinking, communication, as well as enhancing knowledge retention. However, although the students recognize the value of PBL, some of them still favour traditional educational approach due to their conception of learning as knowledge acquisition, determined by China's examination oriented education tradition, and the assessment system in higher education institutes, which still highlights knowledge content accumulation. Students' mixed attitudes may become a significant challenge when one wishes to introduce PBL into the Chinese education system, or to shift traditional teacher-centered learning to student directed learning. To increase students' recognition of PBL in China, one needs not only to show students the effectiveness of the PBL, but also to change the conception of learning in students' mind, which might calls for a radical transformation of the Chinese education system. 


\section{Research limitations and future directions}

Since this study only involves a single disciplinary course in the domain of humanities in China, it might be challenging to generalize the findings in this research to larger context. Therefore, more studies need to be conducted to examine PBL implementation in different curricula contexts (e.g. other types of courses in humanities), other disciplinary fields (e.g. social science), and even other national contexts. Further, as mentioned in the section of research design, the PBL approach in this course is a bit different from some classic PBL approaches: it is a single course based PBL and it rolls out the element of group work, which might also confine the generalizability of this study. In this sense, future design should incorporate more elements of PBL such as group work and holistic design so as to examine PBL effectiveness from more aspects.

\section{Reference}

Alrahlah, A. (2016). How effective the problem-based learning (PBL) in dental education. A critical review. The Saudi dental journal, 28(4), 155-161. Retrieved from: https://doi.org/10.1016/j.sdentj.2016.08.003.

Barge, S. (2010). Principles of Problem and Project Based Learning: The Aalborg PBL Model. Retrived from: https://www.aau.dk/digitalAssets/62/62747_pbl_aalborg_modellen.pdf.

Barrows, H. S., \& Tamblyn, R. M. (1980). Problem-Based Learning: An Approach to Medical Education. New York: Springer.

Bernstein, P., Tipping, J., Bercovitz, K., \& Skinner, H. A. (1995). Shifting students and faculty to a PBL curriculum: attitudes changed and lessons learned. Academic medicine: journal of the Association of American Medical Colleges, 70(3), 245-247. Retrieved from: https://doi.org/10.1097/00001888-199503000-00019.

Biggs, J., \& Tang, C. (2007). Teaching for Quality Learning at University (3rd edition). Maidenhead: Open University Press.

Blumberg, P., \& Michael, J. A. (1992). Development of self - directed learning behaviors in a partially teacher - directed problem - based learning curriculum. Teaching and Learning in Medicine: An International Journal, 4(1), 3-8. Retrieved from: https:// doi.org/10.1080/10401339209539526.

Boud, D. (1985). Problem-Based Learning in Education for the Professions. Sydney: Higher Education Research and Development Society of Australia.

Cohen, L., Manion, L. \& Morrison, K. (2007). Research Methods in Education (6th edition). New York: Routledge. Retrieved from: https://doi.org/10.4324/9780203029053.

Creswell, John (2009). Research Design: Qualitative, Quantitative, and Mixed Methods Approaches. London: Sage.

De Graaff, E., \& Kolmos, A.(2003). Characteristics of Problem-based Learning. International Journal of Engineering Education, 19(5), 657-662. Retrieved from: https:// www.ijee.ie/articles/Vol19-5/IJEE1450.pdf.

De Vries, M. W., Schmidt, H. G., \& De Graaff, E. (1989). Dutch comparisons: Cognitive and motivational effects of problem-based learning on medical students. 
Frontiers of Primary Care, 230-241. Retrieved from: https://doi.org/10.1007/9781-4612-3472-2_16.

Dochy, F., Segers, M., Van den Bossche, P., \& Gijbels, D. (2003). Effects of problem-based learning: A meta-analysis. Learning and instruction, 13(5), 533-568. Retrieved from: https://doi.org/10.1016/s0959-4752(02)00025-7.

Dolmans, D. \& Schmidt, H. (1996). The advantages of problem-based curricula. Postgraduate Medical Journal, 72(851), 535-538. Retrieved from: https://doi.org/10.1136/pgmj.72.851.535.

Dolmans, D. H. J. M., De Grave, W., Wolfhagen, I. H. A. P., \& van der Vleuten, C. P. M. (2005). Problem-based learning: future challenges for educational practice and research. Medical Education, 39(7), 732-741. Retrieved from: https://doi.org/10.1111/j.1365-2929.2005.02205.x.

Du, X., Su, L., \& Liu, J. (2013). Developing sustainability curricula using the PBL method in a Chinese context. Journal of Cleaner Production, 61, 80-88. Retrieved from: https://doi.org/10.1016/j.jclepro.2013.01.012.

Fan, A. P. C., Kosik, R. O., Tsai, T. C. C., Cai, Q., Xu, G. T., Guo, L., ... \& Chen, Q. (2014). A snapshot of the status of problem-based learning (PBL) in Chinese medical schools. Medical teacher, 36(7), 615-620. Retrieved from: https://doi.org/10.3109/0142159X.2014.902045.

Frambach, J. M., Driessen, E. W., Beh, P., \& van der Vleuten, C. P. (2014). Quiet or questioning? Students' discussion behaviors in student-centered education across cultures. Studies in Higher Education, 39(6), 1001-1021. Retrieved from: https:// doi.org/10.1080/03075079.2012.754865.

Frambach, J. M., Driessen, E. W., Chan, L. C., \& van der Vleuten, C. P. (2012). Rethinking the globalisation of problembased learning: how culture challenges self-directed learning. Medical Education, 46(8), 738-747. Retrieved from: https://doi.org/10.1111/j.1365-2923.2012.04290.x.

Hallinger, P. \& Lu, J. (2011). Implementing problem-based learning in higher education in Asia: challenges, strategies and effect. Journal of Higher Education Policy and Management, 33(3), 267-285. Retrieved from: https://doi.org/10.1080/1360080X.2011.565000.

Henriksen, L., Nørreklit, L.,Jørgensen,L.,Christensen, J. \& Donnell, D. (2004). Dimension of Change: Conceptualizing Reality in Organizational Research. Copenhagen: Copenhagen Business School Press.

Kaufman, D. M., \& Mann, K. V. (1996). Comparing students' attitudes in problem-based and conventional curricula. Academic medicine: journal of the Association of American Medical Colleges, 71(10), 1096-1099. Retrieved from: https:// doi.org/10.1097/00001888-199610000-00018.

Kaufman, D. M., \& Mann, K. V. (1997). Basic sciences in problem-based learning and conventional curricula: students' attitudes. Medical education, 31(3), 177-180. Retrieved from: https://doi.org/10.1111/j.1365-2923.1997.tb02562.x.

Kirkpatrick, R., \& Zang, Y. (2011). The negative influences of exam-oriented education on Chinese high school students: Backwash from classroom to child. Language Testing in Asia, 1(3), 36. Retrieved from: https://doi.org/10.1186/2229-0443-1-336.

Klegeris, A.\& Hurren, H. (2011). Impact of problem-based learning in a large classroom setting: student perception and problem-solving skills. Advances in physiology 
education, 35(4), $\quad$ 408-415.

https://doi.org/10.1152/advan.00046.2011.

Kolmos, A. (1996). Reflections on Project Work and Problem-based Learning. European Journal of Engineering Education, 21(2), 141-148. Retrieved from: https://doi.org/10.1080/03043799608923397.

Kolmos, A. \& De Graaff, E. (2007). The Process of Change to PBL. In A. Kolmos \& E. De Graaff (Eds.). Management of Change (pp. 31-44). Rotterdam: Sense Publishers.3144.

Kolmos, A., Fink, F. \& Krog, L. (2004). The Aalborg Model: Problem Based and Project Organized Learning. In A. Kolmos, F. Fink, \& L. Krog (Eds.) The Aalborg PBL Model: Progress, Diversity and Challenges (pp. 9-18). Aalborg: Aalborg University Press.

Kolmos, A. (2008). Problem-based and Project-based Learning: Iinstitutional and Global Change. In O. Skovsmose, P. Valero, \& O. Christensen, (Eds.). University Science and Mathematics Education in Transition (pp. 261-280). New York: Springer.

Li, H. (2013). Educational Change towards PBL (Problem Based Learning): An Organizational Perspective. Aalborg: River Publishers.

Li, H., \& Du, X. (2013). Confronting Cultural Challenges When Restructuring the Teacher-Student Relationship in A Chinese Context. In M. Kirkebæk, X. Du, \& A. Jensen (Eds.), Teaching and Learning Culture: Negotiating the Context (pp. 79-94). Rotterdam: Sense Publisher. Retrieved from: https://doi.org/10.1007/978-946209-440-6_6.

Li, H., \& Du, X. (2015). Teachers' Perspective of their Role and Student Autonomy in the PBL Context in China. International Journal of Learning, Teaching and Educational Research, 10(2), 18-31. Retrieved from: http://www.ijlter.org/index.php/ijlter/article/download/259/103.

Li, H., \& Du, X. (2018). Educational Design for Future: Case Study of the Curriculum Model and Education Idea of Problem Based Learning at Aalborg University in Denmark(面向未来的课程设计：奥尔堡大学 PBL 课程模式与教育理念探 析), Chongqing Higher Education Research (重庆高教研究), (3),117-127.

Moesby, E. (2004). Reflections on Making a Change towards Project Oriented and Problem Based Learning. World transactions on engineering and technology education, 3(2), 269-278. Retrieved from: http://www.wiete.com.au/journals/WTE\&TE/Pages/Vol.3,\%20No.2\%20(2004) /20_Moesby24.pdf.

Mohan, L., Shenoy, S., Eesha, B. R., Bairy, K. L., \& Patil, N. (2014). Students' attitude toward didactic lecture versus problem-based learning in pharmacology: a questionnaire based study. International Journal of Basic $\mathcal{E}$ Clinical Pharmacology, 3(4), 619-622. Retrieved from: https://doi.org/10.5455/23192003.ijbcp20140810.

Preeti, B., Ashish, A., \& Shriram, G. (2013). Problem based learning (PBL)-an effective approach to improve learning outcomes in medical teaching. Journal of clinical and diagnostic research: JCDR, 7(12), 2896-2897. Retrieved from: https:// doi.org/10.7860/jcdr/2013/7339.3787.

Savin-Baden, M. (2000). Problem-based learning in Higher Education: Untold Stories. Buckingham: Open University Press. 
Savin-Baden, M. (2003). Facilitating Problem-based Learning: Illuminating perspectives. The Society for Reseach into Higher Education and Open University Press.

Savin-Baden, M., \& Major, C. (2004). Foundations of Problem Based Learning. Berkshire: McGrawHill Education.

Strobel, J. \& van Barneveld, A. (2009). When is PBL more effective? A Meta-synthesis of Meta-analyses Comparing PBL to Conventional Classrooms. The Interdisciplinary Journal of Problem-based learning, 3(1), 44-58. Retrieved from: https://doi.org/10.7771/1541-5015.1046.

Tiwari, A., Lai, P., So, M., \& Yuen, K. (2006). A comparison of the effects of problem based learning and lecturing on the development of students' critical thinking. Medical Education, 40(6), 547 - $554 . \quad$ Retrieved from: https:// doi.org/10.1111/j.1365-2929.2006.02481.x.

Walker, A., Bridges, E., \& Chan, B. (1996). Wisdom gained, wisdom given: Instituting PBL in a Chinese culture. Journal of educational administration, 34(5), 12-31. Retrieved from: https://doi.org/10.1108/09578239610148250.

Wang, G., Tai B., Huang, C., Bian, Z., Shang, Z., Wang, Q., Song G. (2008). Establishing a Multidisciplinary PBL Curriculum in the School of Stomatology at Wuhan University. International Dental Education, 72(5), 610-615. Retrieved from: http:/ / www.jdentaled.org/content/72/5/610.long.

Woods, D. R. (2012). PBL: An Evaluation of the Effectiveness of Authentic ProblemBased Learning (aPBL). Chemical Engineering Education, 46(2), 135-144. Retrieved from: https://eric.ed.gov/?id=EJ972162.

Zhan, S. (2018). The Application of PBL Model in General Knowledge Courses in Colleges and Universities(PBL 模式在高校通识课程中的应用). Higher Education Exploration (高教探索), (5), 50-55.

Zhou, C., Kolmos, A., \& Nielsen, J. F. D. (2012). A problem and project-based learning (PBL) approach to motivate group creativity in engineering education. International Journal of Engineering Education, 28(1), 3-16. Retrieved from: http://www.forskningsdatabasen.dk/en/catalog/2389342794.

(This research is funded by the General Project of Education Science Research in Shanghai (上海市教育科学研究一般项目). Funding No. C17092 ) 